\title{
Experimental infection of tigerfish (Hydrocynus vittatus) and African sharp tooth catfish (Clarias gariepinus) with Trichinella zimbabwensis
}

\begin{tabular}{|c|c|}
\hline \multicolumn{2}{|c|}{$\begin{array}{l}\text { Authors: } \\
\text { Louis J. la Grange }{ }^{1,2} \text { (D) } \\
\text { Samson Mukaratirwa }{ }^{2,3} \text { (D) }\end{array}$} \\
\hline \multicolumn{2}{|c|}{$\begin{array}{l}\text { Affiliations: } \\
{ }^{1} \text { Department of Agriculture, } \\
\text { Rural Development, Land and } \\
\text { Environmental Affairs, Chief } \\
\text { Directorate Veterinary } \\
\text { Services, Veterinary Public } \\
\text { Health, Mbombela, } \\
\text { South Africa }\end{array}$} \\
\hline \multicolumn{2}{|c|}{$\begin{array}{l}{ }^{2} \text { School of Life Sciences, } \\
\text { College of Agriculture, } \\
\text { Science and Engineering, } \\
\text { University of KwaZulu-Natal, } \\
\text { Durban, South Africa }\end{array}$} \\
\hline \multicolumn{2}{|c|}{$\begin{array}{l}{ }^{3} \text { One Health Center for } \\
\text { Zoonoses and Tropical } \\
\text { Veterinary Medicine, School } \\
\text { of Veterinary Medicine, Ross } \\
\text { University, Basseterre, Saint } \\
\text { Kitts and Nevis }\end{array}$} \\
\hline \multicolumn{2}{|c|}{$\begin{array}{l}\text { Corresponding author: } \\
\text { Samson Mukaratirwa, } \\
\text { mukaratirwa@ukzn.ac.za }\end{array}$} \\
\hline \multicolumn{2}{|c|}{$\begin{array}{l}\text { Dates: } \\
\text { Received: } 20 \text { Apr. } 2020 \\
\text { Accepted: } 17 \text { Aug. } 2020 \\
\text { Published: } 05 \text { Nov. } 2020\end{array}$} \\
\hline \multicolumn{2}{|c|}{$\begin{array}{l}\text { How to cite this article: } \\
\text { La Grange, L.J. \& } \\
\text { Mukaratirwa, S., 2020, } \\
\text { 'Experimental infection } \\
\text { of tigerfish (Hydrocynus } \\
\text { vittatus) and African } \\
\text { sharp tooth catfish } \\
\text { (Clarias gariepinus) with } \\
\text { Trichinella zimbabwensis', } \\
\text { Onderstepoort Journal of } \\
\text { Veterinary Research } 87(1) \text {, } \\
\text { a1876. https://doi.org/ } \\
\text { 10.4102/ojvr.v87i1.1876 }\end{array}$} \\
\hline \multicolumn{2}{|l|}{ Read online: } \\
\hline apping & $\begin{array}{l}\text { Scan this QR } \\
\text { code with your } \\
\text { smart phone or } \\
\text { mobile device } \\
\text { to read online. }\end{array}$ \\
\hline
\end{tabular}

Trichinella zimbabwensis naturally infects a variety of reptilian and wild mammalian hosts in South Africa. Attempts have been made to experimentally infect piranha fish with T. zimbabwensis and T. papuae without success. Tigerfish (Hydrocynus vittatus) and African sharp tooth catfish (Clarias gariepinus) are accomplished predators cohabiting with Nile crocodiles (Crocodylus niloticus) and Nile monitor lizards (Varanus niloticus) in southern Africa and are natural hosts of T. zimbabwensis. To assess the infectivity of T. zimbabwensis to these two hosts, 24 African sharp tooth catfish (mean live weight $581.75 \pm 249.71 \mathrm{~g}$ ) randomly divided into 5 groups were experimentally infected with $1.0 \pm 0.34 \mathrm{~T}$. zimbabwensis larvae per gram (lpg) of fish. Forty-one tigerfish (mean live weight $298.6 \pm 99.3 \mathrm{~g}$ ) were randomly divided for three separate trials. An additional 7 tigerfish were assessed for the presence of natural infection as controls. Results showed no adult worms or larvae of $T$. zimbabwensis in the gastrointestinal tract and body cavities of catfish sacrificed at day 1,2 and 7 post-infection (p.i.). Two tigerfish from one experimental group yielded $0.1 \mathrm{lpg}$ and $0.02 \mathrm{lpg}$ of muscle tissue at day 26 p.i. and 28 p.i., respectively. No adult worms or larvae were detected in the fish from the remaining groups sacrificed at day 7, 21, 28, 33 and 35 p.i. and from the control group. Results from this study suggest that tigerfish could sustain T. zimbabwensis under specific yet unknown circumstances.

Keywords: Clarias gariepinus; Hydrocynus vittatus; tiger fish; infectivity; Trichinella zimbabwensis.

\section{Introduction}

The genus Trichinella belongs to the family Trichinellidae and the Order Trichuridae, class Nematode (Pozio et al. 2009). Trichinella establishes in the host when larvae in raw or undercooked meat are consumed (Dupoy-Camet 2000). Parasites in the genus complete both intermediate and definitive life cycle stages in a single host. Larvae are intracellular parasites of striated muscle tissue and adult nematodes parasitise the intestinal epithelium (Gottstein, Pozio \& Nöckler 2009).

Trichinella zimbabwensis has the widest host range and is the most prevalent of the three known Trichinella spp. (i.e. T. nelsoni, T. zimbabwensis and Trichinella T8) in the Greater Kruger National Park (GKNP). It naturally infects various reptilian and wild mammalian hosts in South Africa (La Grange \& Mukaratirwa 2020; Mukaratirwa et al. 2019). Amongst the confirmed natural hosts, the highest prevalence has been recorded in Nile crocodile (Crocodylus niloticus) (La Grange, Govender \& Mukaratirwa 2013).

In the last two decades, significant strides were made in identifying natural hosts of Trichinella spp. in the GKNP (Mukaratirwa et al. 2019) and continued surveillance to identify additional hosts for T. zimbabwensis is still required (La Grange \& Mukaratirwa 2020; La Grange et al. 2013). Previous experimental studies involving fish elsewhere showed some Trichinella species are able to survive for short periods in the gut (Moretti et al. 1997; Tomašovičová 1981), suggesting some tropical fish to act as definitive or paratenic hosts for the parasite.

Pienaar (1968) reported the presence of 46 fish species, including predatory species such as African sharp tooth catfish (Clarias gariepinus), tigerfish (Hydrocynus vittatus), Madagascar mottled eel (Anguilla marmorata) and common long fin eel (A. mossambicus) in the KNP. 
Catfish are accomplished scavengers and predators, and consume a variety of food ranging from plankton to small mammals (Bruton 1979; Skelton 2001). Tigerfish are apex predators that occupy the same trophic level as Nile crocodiles where they cohabit (Roux et al. 2018). The feeding behaviour of these fish makes them potential hosts of T. zimbabwensis.

This study aimed at assessing the infectivity of T. zimbabwensis to catfish and tigerfish which cohabit natural environments with Nile crocodile, a known natural host of the parasite.

\section{Materials and methods}

Twenty-four African sharp tooth catfish from a research breeding and holding facility of the University of Limpopo, South Africa were housed outdoors in moveable ponds at a research facility at Tipperary farm, Nelspruit, South Africa. They were fed commercial koi pellets daily (Aqua Plus, Midfeeds, South Africa).

Tigerfish were collected from two sites along the Komati river $\left(31^{\circ} 55^{\prime} 07.1^{\prime \prime} \mathrm{E}, 25^{\circ} 29^{\prime} 41.4^{\prime \prime} \mathrm{S}\right.$ and $\left.31^{\circ} 58^{\prime} 02.3^{\prime \prime} \mathrm{E}, 25^{\circ} 29^{\prime} 12.8^{\prime \prime} \mathrm{S}\right)$ and housed indoors on a private farm near one of the collection sites. Ponds were equipped with an inline filtration system and submersible pump $(6500 \mathrm{~L} / \mathrm{h})$. A water heater (UltraZap, $3 \mathrm{kw}$ ) was additionally installed during two of the trials to maintain average water temperature within the fish's natural range.

Water temperature was recorded for $4 \mathrm{~h}$ intervals in the ponds and Komati River using temperature loggers (Hobo Water temp pro V2, Onsetcomp).

Trichinella zimbabwensis larvae, previously derived from a Nile crocodile, were maintained in a colony of rats housed at the Biological Resource Unit (BRU) at the Westville Campus of the University of KwaZulu-Natal. Infected rats were euthanised and larvae isolated using artificial muscle digestion (Nöckler \& Kapel 2007).

Additional Trichinella-infected muscle tissue was collected and mixed into a homogenous, pooled sample containing 50 larvae per gram (lpg) to infect catfish via natural feeding.

Ten catfish were infected using an orogastric tube (Table 1). Fish in Group $1(n=5)$ were sedated with $0.3 \mathrm{~mL} / 1$ of 2-phenoxyethanol in water. Once stage 2 anaesthesia was reached (Gardner 2017), the fish were individually infected with approximately 500 larvae administered via a canine urinary catheter (Sovereign $^{\circledast}$, French Gauge 8, Sherwood Medical, St. Louis, United States of America). The procedure was repeated for Group $2(n=5)$ but without anaesthetic, to rule out possible negative effects of anaesthetic on the establishment and/or development of $T$. zimbabwbensis larvae.

An additional 10 fish were infected using blank gelatin capsules (size 0, Medisurge, South Africa). Capsules containing approximately 500 larvae were administered orally. Group $3(n=5)$ was infected with, and Group $4(n=5)$, without anaesthesia (Table 1).

Four fish (Group 5) were infected through natural feeding with approximately 1000 larvae/fish (Table 1). Ten grams of infective tissue (50 lpg) was used to prepare infective boluses (approximately 500 larvae). Two boluses were offered to each fish on the day of infection and were readily consumed by the fish.

Fresh chicken hearts (Mikon Farming abattoir, South Africa) were 'loaded' with a $2 \mathrm{~mL}$ solution of infective material (approximately 300 larvae/mL) using a $3 \mathrm{~mL}$ syringe and 25 gauge needle. Each fish received a single infected chicken heart. Three separate trials were conducted (Table 2).

Tigerfish intended for trial $1\left(\mathrm{~T}_{1}\right)(n=1)$, trial $2\left(\mathrm{~T}_{2}\right)(n=3)$ and trial $3\left(\mathrm{~T}_{3}\right)(n=3)$ died during the respective first weeks of acclimation because of stress, preserved (frozen) and retained as a control group.

Fish were euthanised on day 1, 2 and 7 p.i. (catfish) and 7, 21, 28,33 and 35 p.i. (tigerfish) using $0.6 \mathrm{~mL} / 1$ of 2 -phenoxyethanol. Fish were allowed to reach stage 4 anaesthesia (Gardner 2017) before being decapitated.

Each fish was dissected ventrally and opened lengthwise from the cloaca to the head. The body cavity was rinsed with $0.9 \%$ saline solution and the wash collected in a glass Petri dish. The small intestines and stomach were separated into specimen dishes containing $0.9 \%$ saline solution (Justine, Briand \& Bray 2012), cut open and the mucosa carefully scraped. The contents and the wash liquid were examined for the presence of $T$. zimbabwensis larvae and/or adults. Additionally, a representative sample of the whole body comprising $100 \mathrm{~g}$ of muscle tissue was collected, artificially

TABLE 1: Results from experimental infection of African sharp tooth catfish (Clarias gariepinus) with Trichinella zimbabwensis.

\begin{tabular}{|c|c|c|c|c|c|c|c|c|c|c|}
\hline \multirow[t]{2}{*}{ Group } & \multirow[t]{2}{*}{$\mathbf{N}$} & \multirow[t]{2}{*}{$M / F$} & \multirow{2}{*}{$\begin{array}{c}\text { Weight } \\
\text { (g) } \bar{x} \pm S D\end{array}$} & \multirow[t]{2}{*}{ Infection method } & \multirow{2}{*}{$\begin{array}{l}\text { Lpg of fish } \\
\overline{\mathbf{x}} \pm \text { SD }\end{array}$} & \multirow{2}{*}{$\begin{array}{c}T^{\circ} \mathrm{C} \\
\overline{\mathrm{x}} \pm \mathrm{SD}\end{array}$} & \multirow[t]{2}{*}{ Day (p.i.) } & \multicolumn{3}{|c|}{ Infection results } \\
\hline & & & & & & & & Body cavity & Intestines & Muscle \\
\hline Group 1 & 5 & $3 / 0$ & $354.9 \pm 75.46$ & Orogastric (anaesthesia) & $1.26 \pm 0.58$ & $22.47 \pm 1.28$ & 7 & Neg & Neg & Neg \\
\hline Group 2 & 5 & $5 / 0$ & $531.0 \pm 160.3$ & Orogastric (no anaesthesia) & $1.02 \pm 0.29$ & $15.59 \pm 0.50$ & 7 & Neg & Neg & Neg \\
\hline Group 3 & 5 & $5 / 0$ & $568.0 \pm 109.7$ & Gelatin capsules (anaesthesia) & $0.92 \pm 0.20$ & $15.49 \pm 0.36$ & 2 & Neg & Neg & Neg \\
\hline Group 4 & 5 & $3 / 2$ & $499.6 \pm 74.1$ & Gelatin capsules (no anaesthesia) & $1.02 \pm 0.14$ & $15.55 \pm 0.41$ & 1 & Neg & Neg & Neg \\
\hline Group 5 & 4 & $4 / 0$ & $1048.0 \pm 137.8$ & Natural Feeding & $1.00 \pm 0.11$ & $21.58 \pm 1.36$ & 2 & Neg & $\mathrm{Neg}$ & $\mathrm{Neg}$ \\
\hline
\end{tabular}

$\mathrm{M} / \mathrm{F}$, male/female; SD, standard deviation; Neg, negative for infection; p.i., post-infection; Ipg, larvae per gram. 
TABLE 2: Results from experimental infection of tigerfish (Hydrocynus vittatus) with Trichinella zimbabwensis.

\begin{tabular}{|c|c|c|c|c|c|c|c|c|c|c|}
\hline \multirow[t]{2}{*}{ Trial (T)/Group (G) } & \multirow[t]{2}{*}{$\mathbf{N}$} & \multirow[t]{2}{*}{$M / F$} & \multirow{2}{*}{$\begin{array}{c}\text { Weight(g) } \\
\bar{x} \pm S D\end{array}$} & \multirow{2}{*}{$\begin{array}{l}\text { Lpg of fish } \\
\overline{\mathbf{x}} \pm S D\end{array}$} & \multirow{2}{*}{$\begin{array}{l}T\left({ }^{\circ} \mathrm{C}\right) \\
\overline{\mathrm{x}} \pm \mathrm{SD}\end{array}$} & \multirow[t]{2}{*}{ Day (p.i.) } & \multirow[t]{2}{*}{ No tested } & \multicolumn{3}{|c|}{ Infection results } \\
\hline & & & & & & & & Body cavity & Intestines & Muscle \\
\hline $\mathrm{T}_{1} \mathrm{G}_{1}$ & 8 & $5 / 3$ & $301.3 \pm 95.7$ & $2.2 \pm 0.9$ & $25.6 \pm 1.6$ & 28 & 4 & Neg & Neg & $0.02 \dagger ; 0.1 \dagger+\operatorname{lpg}$ \\
\hline $\mathrm{T}_{2} \mathrm{G}_{1}$ & 5 & $4 / 1$ & $265.4 \pm 103.5$ & $2.7 \pm 1.1$ & $25.1 \pm 1.3$ & 28 & 5 & Neg & Neg & Neg \\
\hline $\mathrm{T}_{2} \mathrm{G}_{2}$ & 6 & $4 / 1$ & $242.0 \pm 105.4$ & $2.9 \pm 1.2$ & $24.9 \pm 1.2$ & 35 & 6 & $\mathrm{Neg}$ & Neg & Neg \\
\hline $\mathrm{T}_{3} \mathrm{G}_{1}$ & 5 & $4 / 1$ & $356.3 \pm 71.9$ & $0.6 \pm 0.1$ & $26.9 \pm 0.4$ & 7 & 5 & Neg & Neg & Neg \\
\hline $\mathrm{T}_{3} \mathrm{G}_{2}$ & 5 & $1 / 4$ & $305.7 \pm 103.3$ & $2.2 \pm 0.9$ & $26.4 \pm 0.9$ & 21 & 5 & Neg & Neg & Neg \\
\hline $\mathrm{T}_{3} \mathrm{G}_{3}$ & 5 & $3 / 2$ & $330.5 \pm 56.7$ & $1.9 \pm 0.3$ & $26.4 \pm 1.6$ & 33 & 5 & Neg & $\mathrm{Neg}$ & $\mathrm{Neg}$ \\
\hline
\end{tabular}

Results for control fish $(n=7)$ not included in the above results. Controls were negative.

$T_{1} G_{1}$, Trial 1 Group 1; $T_{1} G_{2}$, Trial Group 2; $T_{3} G_{1}$, Trial 3 Group 1; $T_{3} G_{2}$, Trial 3 Group 2; $T_{3} G_{3}$, Trial 3 Group 3.

$\mathrm{M} / \mathrm{F}$, male/female; SD, standard deviation; Neg, negative for infection; p.i., post-infection; Ipg, larvae per gram.

$\dagger$, Muscle larvae observed on day 28 p.i.

$\dagger$, Muscle larvae observed on day $26 \mathrm{p} . \mathrm{i}$.

digested (Nöckler \& Kapel 2007) and examined for the presence of T. zimbabwensis larvae.

The average weight \pm standard deviation (SD) was expressed per group. Water temperature was expressed as average daily water temperature \pm SD for each group. Mean temperature of the ponds during each trial was compared with the mean temperature of the river during the corresponding time frame using student T-tests.

\section{Ethical consideration}

The study protocol was approved by the Animal Research Ethics Committee of the University of KwaZulu-Natal (Ref: AREC/029/016M and 030/019D).

\section{Results and discussion}

Results from the experimental trials are shown in Tables 1 and 2. No larvae or adults of T. zimbabwensis were observed in the gastrointestinal tract, body cavities and muscle tissue of catfish infected using different modes at day 1, 2 or 7 p.i. (Table 1). Because of prolonged national power failures during the last 2 weeks of $T_{1} G_{1}$, four tigerfish died at day 23 p.i and two at day 26 p.i. from oxygen depletion of the water. The two surviving fish were euthanised at day 28 p.i.

Analysis of the two tigerfish that died on day 26 p.i. yielded a total of 10 dead larvae (1 lpg of muscle) from one fish. Of the two that were euthanised one fish yielded a live larva $(0.02 \mathrm{lpg})$ in muscle tissue. The low number of larvae recovered is in agreement with findings from studies involving T. britovi (Moretti et al. 1997) and T. spiralis and T. pseudospiralis (Tomašovičová 1981). No larvae or adult parasites were observed in the body cavity, stomach or gastrointestinal tract of fish euthanised at day $7,28,33$ or 35 p.i.

The minimum infective larval dose required in a specific host is dependant on both parasite- and host characteristics (Gottstein et al. 2009). Previous studies involving fish experimentally infected with T. pseudospiralis and T. spiralis (Tomašovičová 1981), T. britovi (Moretti et al. 1997) and T. zimbabwensis and T. papuae (Pozio \& La Rosa 2005) were reported on varying dosages of Trichinella larvae administered to fish and no mention was made of the live weight of fish used. The lack of data in respect of the weight of fish and larvae per gram of fish administered in previous studies precludes a comparison to assess the minimum infective dosage needed for T. zimbabwensis to establish in fish.

In an experimental study involving T. zimbabwensis and T. papuae, reptiles were successfully infected with an inoculum of 3000 larvae per animal (Pozio et al. 2004). This dose might have been greater than inocula used for catfish and tigerfish in this study although information on the weight of animals was not given. Previous studies in other poikilothermic hosts, experimentally infected with different Trichinella taxa, suggest that temperature plays an integral role in larval survival and/or development in the host (Asatrian, Movsessian \& Gevorkian 2000; Cristeau \& Perian 1999; Pozio et al. 2004). In this study, water temperatures in ponds where catfish were kept were lower than those reported by Tomašovičová (1981) and Moretti et al. (1997).

Temperatures recorded during tigerfish trials in this study were much higher than those reported in the studies conducted by Tomašovičová (1981) and Moretti et al. (1997) and compared favourably with the lower end of temperatures reported by Pozio and La Rosa (2005). Water temperature in the river was significantly higher compared to the experimental ponds for $\mathrm{T}_{1}(p=0.002), \mathrm{T}_{2} \mathrm{G}_{1}(p=0.0002), \mathrm{T}_{2} \mathrm{G}_{2}$ $(p=0.002), \mathrm{T}_{3} \mathrm{G}(p=0.04)$ and $\mathrm{T}_{3} \mathrm{G}_{3}(p<0.0001)$, but not so for $\mathrm{T}_{3} \mathrm{G}_{1}(p=0.07)$. This precludes any definitive conclusion concerning the influence of temperature on T. zimbabwensis larval development and survival in fish.

Previous studies also suggested several host-related factors for the failure of T. zimbabwensis to establish in fish and this includes: (1) lack of villi in the small intestine preventing larvae from anchoring to the intestinal wall and resist peristaltic movements, (2) the copious amounts of bile and mucous excreted in the intestine of fish, (3) low body temperature of the host, (4) quick passage of larvae through the intestine and (5) possible destruction of larvae by digestive processes (Moretti et al. 1997).

Trichinella pseudospiralis larvae have been reported to migrate without moulting from the gastrointestinal tract to the body cavity, organs and muscles of fish whilst T. spiralis larvae only migrated to the body cavity of fish 
(Tomašovičová 1981). Trichinella britovi larvae migrated without further development and were isolated from the gastrointestinal tract and body cavity of carp (Cyprinus carpio) and from the gastrointestinal tract of catfish (Ictalurus melas) (Moretti et al. 1997). In this study, no positive results could be obtained from the fish during the early stages after infection (day 1, 2 and 7 p.i.) in catfish or day 7 p.i. in tigerfish.

From an epidemiological perspective, the negative results from this study in catfish rule out the potential of this fish species as a host for T. zimbabwensis. Positive results from tigerfish, although interesting, are inconclusive on whether tigerfish could act as reservoir hosts for T. zimbabwensis.

\section{Conclusion}

Results from this study suggest that $T$. zimbabwensis is unable to develop and establish in the African sharp tooth catfish, however, results from tigerfish suggest that some individual fish could, under very specific circumstances, maintain T. zimbabwensis larvae. It is not known whether the parasite can fully develop and reproduce in this host.

The paucity of information concerning the minimum infective dosage required to establish $T$. zimbabwensis infection, the potential influence of host (Kapel 1995; La Grange et al. 2013; Reina, Munoz-Ojeda \& Serrano 1996; Soule et al. 1989) and parasite characteristics (Hurnikova et al. 2004; Kapel, Webster \& Gamble 2005) and the potential influence of temperature on larval development and survival in fish precludes a general hypothesis that fish do not play any role in the epidemiology of T. zimbabwensis. Future research efforts should focus on additional tropical fish that cohabit with other known hosts of T. zimbabwensis in the GKNP to elucidate the role of any specific fish species in the epidemiology of T. zimbabwensis.

\section{Acknowledgements}

The authors would like to acknowledge the Mpumalanga Department of Agriculture, Rural Development, Land and Environmental Affairs for logistical and financial support provided through the Chief Directorate of Veterinary Services, and Dr J.P. Raath and staff of Wildlifevets.com and Wildlife Pharmaceuticals for financial, logistical and technical support provided.

\section{Competing interests}

The authors have declared that no competing interests exist.

\section{Authors' contributions}

L.L.J. and S.M. conceived and designed the study. L.L.J. carried out the experiments and analysed the data and drafted the manuscript. All authors were involved in the revision and approval of the final version of the manuscript.

\section{Funding information}

This research received no specific grant from any funding agency in the public, commercial or not-for-profit sectors.

\section{Data availability statement}

Data sharing is not applicable to this article as no new data were created or analysed in this study.

\section{Disclaimer}

The views and opinions expressed in this article are those of the authors and do not necessarily reflect the official policy or position of any affiliated agency of the authors.

\section{References}

Asatrian, A., Movsessian, S. \& Gevorkian, A., 2000, 'Experimental infection of some reptiles with $T$. spiralis and $T$. pseudospiralis', Abstract book, The Tenth International conference on Trichinellosis, Fontaineblue, 20-24 August, p. 154.

Bruton, M.N., 1979, 'The food and feeding behaviour of Clariasgariepinus (Pisces: Clariidae) in Lake Sibaya, South Africa, with emphasis on its role as a predator of cichlids', Transactions of the Zoological Society of London 35(1), 47-114. https:// doi.org/10.1111/j.1096-3642.1979.tb00057.x

Cristeau, G. \& Perian, A., 1999, 'Experimental infestation with Trichinella in vipers', Revista Romana de Parsitologia 9, 45.

Dupouy-Camet, J., 2000, 'Trichinellosis: A worldwide zoonosis', Veterinary Parasitology 93(3-4), 191-200. https://doi.org/10.1016/S0304-4017(00)00341-1

Gardner, B.R., 2017, Anaesthesia of fresh water teleost fish for the private practitioner Copyright Reserved, South African Veterinary Association, 6 pages, viewed 17 February 2018, from http://www.cpdsolutions.co.za/Publications/org publications public.php?o=51.

Gottstein, B., Pozio, E. \& Nöckler, K., 2009, 'Epidemiology, diagnosis, treatment, and control of trichinellosis', Clinical Microbiology Review 22(1), 127-145. https://doi. org/10.1128/CMR.00026-08

Hurníková, Z., Dubinsky, S., Mukaratirwa, S., Foggin, C.M. \& Kapel, C.M.O., 2004 'Infectivity and temperature tolerance on non-encapsulating Trichinella zimbabwensis in experimentally infected Red foxes (Vulpes vulpes)', Helminthologia 41(4), 189-192.

Justine, J., Briand, M.J. \& Bray, R.A., 2012, 'A quick and simple method, usable in the field, for collecting parasites in suitable condition for both morphological and molecular studies', Parasitology Research 111, 341-351. https://doi.org/10.1007/ molecular studies', $P$ ard

Kapel, C., 1995, 'Trichinella infections in Arctic foxes from Greenland: Studies and reflections on predilection sites of muscle larvae', Journal of Helminthology 69(4), 325-330. https://doi.org/10.1017/S0022149X00014905

Kapel, C., Webster, P. \& Gamble, H., 2005, 'Muscle distribution of sylvatic and domestic Trichinella larvae in production animals and wildlife', Veterinary Parasitology 132(1-2), 101-105. https://doi.org/10.1016/j.vetpar.2005.05.036

La Grange, L.J. \& Mukaratirwa, S., 2020, 'Epidemiology and hypothetical transmission cycles of Trichinella infections in the Greater Kruger National Park of South Africa: An example of host-parasite interactions in an environment with minimal human interference', Parasite 27(13), 1-12. https://doi.org/10.1051/parasite/2020010

La Grange, L.J., Govender, D. \& Mukaratirwa, S., 2013, 'The occurrence of Trichinella zimbabwensis in naturally infected wild crocodiles (Crocodylusniloticus) from the Kruger National Park, South Africa', Journal of Helminthology 87(1), 91-96. https://doi.org/10.1017/\$0022149X12000089

Moretti, A., PiergiliFioretti, D., Pasquali, P., Mechelli, L., Rossodivita, M.E. \& Polidori, G.A., 1997, 'Experimental infection of fish with Trichinella britovi: Biological evaluations', in G. Ortega-Pierres, H.R. Gamble, F. Van Knapen \& D. Wakelin (eds.), Trichinellosis. Centro de Investigacion y Estudios Avanzados del Instituto Politecnico Nacional, pp. 135-142, Mexico City.

Mukaratirwa, S., La Grange, L.J., Malatji, M.P., Reininghaus, B. \& Lamb, J., 2019, 'Prevalence and molecular identification of Trichinella species isolated from wildlife originating from Limpopo and Mpumalanga provinces of South Africa', Journal of Helminthology 93(1), 50-56. https://doi.org/10.1017/S0022149X17001079

Nöckler, K. \& Kapel, C.M.O., 2007, 'Detection and surveillance for Trichinella: Meat inspection hygiene, and legislation' in J. Dupouy-Camet \& K.D. Murrell (eds.), FAO/ WHO/OIE guidelines for the surveillance, management, prevention and control of trichinellosis, pp. 69-97, World Organisation for Animal Health Press, Paris.

Pienaar, U. de V., 1968, The freshwater fishes of the Kruger National Park, pp. 1-20, National Parks Board, Pretoria.

Pozio, E. \& La Rosa, G., 2005, 'Evaluation of the infectivity of Trichinella papuae and Trichinella zimbabwensis for equatorial freshwater fishes', Veterinary Parasitology 132(1-2), 113-114. https://doi.org/10.1016/j.vetpar.2005.05.038 
Pozio, E., Hoberg, E., La Rosa, G. \& Zarlenga, D.S., 2009, 'Molecular taxonomy, phylogeny and biogeography of nematodes belonging to the Trichinella genus', Infection, Genetics and Evolution 9(4), 606-616. https://doi.org/10.1016/j.meegid.2009.03.003

Pozio, E., Marucci, G., Casulli, A., Sacchi, L., Mukaratirwa, S., Foggin, C.M. et al., 2004 'Trichinella papuae and Trichinella zimbabwensis induce infection in experimentally infected varans, caimans, pythons and turtles', Parasitology 128(3), 333-342. https://doi.org/10.1017/S0031182003004542

Reina, D., Munoz-Ojeda, M. \& Serrano, F., 1996, 'Experimental trichinellosis in goats', Veterinary Parasitology 62(1-2), 125-132. https://doi.org/10.1016/03044017(95)00835-7
Roux, F., Steyn, G., Hay, C. \& Wagenaar, I., 2018, 'Movement patterns and home range size of tiger fish (Hydrocynusvittatus) in the Incomati River system, South Africa', Koedoe 60(1), 1-13. https://doi.org/10.4102/koedoe.v60i1.1397

Skelton, P., 2001, A complete guide to the freshwater fishes of Southern Africa, 2nd edn., Struik Publishers, Cape Town.

Soule, C., Dupoy-Camet, J., Georges, P., Ancelle, T., Gillet, J.P., Vaissaire, J. et al., 1989, 'Experimental trichinellosis in horses: Biological and parasitological evaluation Veterinary Parasitology 31(1), 19-36. https://doi.org/10.1016/0304-4017(89)90005-8

Tomašovičová, O., 1981, 'The role of fish in transfer and maintenance of Trichinellae under natural conditions', Biologia 36(2), 115-125. 